Mycologia, 77(1), 1985, pp. 83-96.

(C) 1985, by The New York Botanical Garden, Bronx, NY 10458

\title{
STUDIES OF PALEOZOIC FUNGI IV: WALL ULTRASTRUCTURE OF FOSSIL ENDOGONACEOUS CHLAMYDOSPORES
}

\author{
SARA P. STUBBLEFIELD, THOMAS N. TAYLOR, \\ Department of Botany, The Ohio State University, \\ Columbus, Ohio 43210
}

AND

CHARLES E. MILLER

Department of Botany, Ohio University, Athens, Ohio 45701

\begin{abstract}
Fossil endogonaceous chlamydospores are described from the aerial axes and roots of several Paleozoic plants preserved in calcilutite nodules and calcareous coal balls. Specimens come from six Paleozoic localities extending from the uppermost Lower Devonian through the Upper Pennsylvanian. Although fossil chlamydospores are markedly similar to the modern Endogonaceae in transmitted light, ultrastructural comparisons have not previously been made. The fine structure of the walls of these spores is consistent with past interpretations which relate them to the modern Endogonaceae, but thorough comparisons cannot be made due to the lack of comparable ultrastructural information from extant VA mycorrhizae. The evidence from mycorrhizal associations in the fossil record is evaluated.
\end{abstract}

Key Words: chlamydospore, Endogonaceae, fossil fungi, vesicular-arbuscular mycorrhizae, wall ultrastructure.

The presence of fungal chlamydospores in permineralized Paleozoic plants has been noted repeatedly since the early 1900s. Such structures are probably best known from the Devonian Rhynie Chert (Kidston and Lang, 1921), and have aroused considerable interest because of their resemblance to extant vesiculararbuscular (VA) mycorrhizal fungi. Butler (1939) was perhaps the first to suggest that such bodies were fossil representatives of the modern Endogonaceae, while others have reported similar fungi and considered the possibility of endomycorrhizal relationships in the Paleozoic (Weiss, 1904; Lignier, 1906; Osborn, 1909; Halket, 1930; Zimmermann, 1933; Andrews and Lenz, 1943; Wolf and Wolf, 1947; Kelly, 1950; Boullard and Lemoigne, 1971). More recently, Pirozynski and Malloch (1975) have argued for the presence of VA mycorrhizae associated with plants in the Paleozoic, and have suggested that the establishment of mycorrhizal relationships was a major factor in the development of the vascular land flora. We can evaluate this suggestion only insofar as it is possible to recognize fossil mycorrhizae and distinguish them from other root endophytes (Berch and Kendrick, 1982). In the past, comparisons have been made primarily through light microscopy and have centered on gross morphological detail. The use of scanning and transmission electron microscopy provides an opportunity to make ultrastructural comparisons as well, particularly with respect to the wall structure of chlamydospores.

The relevance of wall structure to questions of fungal phylogeny and the 
systematics of the Endogonaceae has been recognized by various authors (Bartnicki-Garcia, 1970; Mosse, 1970c; Walker, 1983). Recently, fossil Glomus-like chlamydospores from three Pennsylvanian age localities were studied by Wagner and Taylor (1981, 1982) using both transmitted light and scanning electron microscopy. The similarity between the fossil and extant chlamydospores with respect to wall structure and hyphal attachment was substantial, and indicated that the Pennsylvanian specimens probably represent endogonaceous chlamydospores most similar to the extant genus, Glomus (Wagner and Taylor, 1982). Our analysis was undertaken to extend these comparisons to the ultrastructural level, and to include material from a wider geological and geographical range. This type of study provides the opportunity to document the structure of fossil endogonaceous chlamydospores from the early Devonian throughout most of the Pennsylvanian, and to evaluate the relationship between these fossils and modern VA mycorrhizae.

\section{MATERIALS AND METHODS}

Fossil chlamydospores were obtained from a calcilutite cobble from the $\mathrm{Ca}$ nadian Gaspe Peninsula, and from coal balls collected at Lewis Creek, Kentucky; West Mineral, Kansas; Berryville and Calhoun, Illinois; and Steubenville, Ohio. The Gaspe material is found high in the Battery Point Formation which lies near the top of Emsian strata (late early Devonian) (McGregor, 1977; Stubblefield and Banks, 1983). The Lewis Creek locality is one of the oldest in North America and is either uppermost Lower Pennsylvanian (Good and Taylor, 1970), or lowermost Middle Pennsylvanian (Westphalian B equivalent) (Phillips, 1980). West Mineral is somewhat higher in the Middle Pennsylvanian (Westphalian C equivalent) (Good, 1975), while Berryville (Mamay, 1957) and New Calhoun (Phillips, 1980) are both Upper Pennsylvanian (Stephanian equivalent). The youngest material examined in this study comes from the Upper Pennsylvanian (Stephanian equivalent) Steubenville locality (Rothwell, 1976). These localities span approximately 70 million years.

Before specimens were prepared for scanning electron microscopy several cellulose acetate peels were made of each cluster of chlamydospores and mounted in Harleco Synthetic Resin for examination in transmitted light. The Devonian peels were treated as described by Stubblefield and Banks (1983). Pennsylvanian age specimens were etched in dilute $(2 \%)$ hydrochloric acid, dehydrated in a graded series of ethanol, dried with an Autosamdri critical point drier, coated with gold, and mounted on standard SEM stubs. After the specimens were examined, gold was removed in a $10 \%$ solution of sodium cyanide (Sela and Boyde, 1977). The same specimens were then prepared for transmission electron microscopy.

Specimens were freed from the matrix for TEM examination in several ways depending upon the delicacy of the chlamydospore walls. In some instances it was possible to remove entire spores, or large fragments of them, by slowly dissolving the rock matrix with dilute hydrochloric acid. This was particularly effective with material from Steubenville and West Mineral. In most cases, however, the spores were too delicate to be removed whole (Wagner and Taylor, 1982). More fragile specimens were etched gently with $\mathrm{HCl}$, dehydrated in acetone and peeled with cellulose acetate. Appropriate areas of the peel were placed on a cellulose Millipore filter and embedded in 2\% agar under suction. Material from Lewis Creek was particularly fragile and did not withstand deep etching and peeling. To isolate intact chlamydospores from this locality a small block of coal ball was removed and etched as deeply as possible without destroying the spores. The entire block was then encased in agar and dehydrated in ethanol. The agar, 
toughened by dehydration, was then cut from the surface of the block and the appropriate areas were excised. Once encased in agar, all samples were stained in $2 \%$ uranyl acetate for $4 \mathrm{~h}$ at room temperature $(75 \mathrm{~F})$. They were then dehydrated and embedded in Spurr low viscosity plastic following standard procedures. During infiltration both the cellulose filter and the cellulose acetate peel usually dissolved. When a thin remnant of either persisted it did not interfere with ultramicrotomy, and was sometimes beneficial in maintaining the structural integrity and three-dimensional organization of the chlamydospores. The techniques used in freeing and embedding the present material are similar to those described by Daghlian and Taylor (1979) for pollen grains and spores. However, the peel is not dissolved until the material is embedded in agar. This is accomplished on a cellulose Millipore filter which will later dissolve as the sample is passed through acetone. These modifications increase the likelihood of retaining the original threedimensional orientation of the fossil tissues. Sectioned chlamydospores were examined at $75 \mathrm{kV}$.

\section{DESCRIPTION}

Chlamydospores occur in small groups in the cortical regions of Pennsylvanian stigmarian rootlets and Psaronius roots, and in the inner cortex of several aerial axes of the Devonian trimerophyte, Psilophyton dawsonii. Specimens from each locality are similar in organization and wall structure. They are typically spherical and lack pre-formed openings. Walls are consistently unornamented and internal contents are absent. Although it was not always possible to characterize fully each of the walls of every type of chlamydospore due to imperfect preservation and the difficulties of preparing specimens, two different types of wall components are clearly visible at the ultrastructural level. The first is an electron-dense, homogeneous unit with no apparent structural detail (FIG. 3). This is the sole component of walls of the Devonian material and is a part of the wall of every other chlamydospore examined. The second component consists of more loosely organized material which forms one to several spongy layers (FIG. 26). Although the fossil spores are consistent in the general pattern of wall organization, spores from different localities differ in the precise number, thickness, and order of these layers. Specimens from each locality will be discussed individually.

Gaspe (FIGS. 1-3).-A detailed description of fungal chlamydospores from this locality as seen in transmitted light and scanning electron microscopy is provided by Stubblefield and Banks (1983). Specimens are up to $175 \wedge \mathrm{m}$ in diam and possess two walls, each approximately 2-3/im thick. Each separates into a variable number of layers which are visible when specimens are scanned (FIG. 2), but are not apparent in transmitted light (FIG. 1). At the ultrastructural level, three discrete layers composed of an electron-dense, homogeneous material are seen which together constitute a portion of the thick outer wall (FIG. 3). The outer layer visible in FIG. 3 is approximately 0.3 finI, while the inner two layers are each approximately 0.1 /ini. Each layer is composed of an amorphous, electron-dense, solid material.

Lewis Creek (FIGS. 4-9).-Chlamydospores from Lewis Creek reach 260 iim in diam and typically have a thick outer wall approximately 3 ixm thick and a thinner, more delicate inner wall of approximately $0.5 \mathrm{nnI}$. While most specimens are twowalled, a third wall is sometimes present (FIG. 5). A similar wall was occasionally observed by Wagner and Taylor (1982), and may be either an additional wall or a torn fragment of the second wall. In a two-walled spore a portion of each wall is composed of an amorphous, electron-dense material similar to that comprising 
the entire wall of a Gaspe chlamydospore (FIGS. 7-9). Adjacent to these layers is a zone of more loosely arranged wall material. Considerable tearing and disruption is visible in the walls of these spores at the ultrastructural level.

West Mineral (FIGS. 10-14, 18).-Chlamydospores from West Mineral are up to 200 ium in diam and possess two or three walls. The outer layer is 5-8/xm thick, while the inner two walls reach only approximately 1-2/im. The most notable feature of the outer wall is its loose construction and spongy appearance (FIGS. 12-14). The middle wall is also apparently somewhat porous (FIG. 11), although it is not clear whether this reflects the actual organization of the wall, or is a result of preservation or changes caused by preparation. Ultrastructural examination of a portion of the outer wall reveals a complex structure which includes both solid, homogeneous regions and more loosely arranged areas (FIG. 18).

Berryville (FIGS. 15-17). - Chlamydospores from Berryville reach $320^{\wedge} \mathrm{m}$ in diam and are customarily two-walled (FIG. 16). Both walls are approximately the same thickness and range from 2-3 ixm. Evidence of degradation is present even in transmitted light (FIG. 16). Ultrathin sections reveal portions of this organization including an outer spongy region which was often not preserved, a solid, homogeneous layer, and an inner, loosely organized area bounded by a thin, solid unit (FIG. 15). The thickness of the sectioned unit suggests that both the outer and inner wall of a spore are represented. However, both walls were not apparent when the spore was examined in transmitted light, although they may have been closely appressed. Alternatively, this unit may represent only one wall and be unnaturally wide due to separation during preservation or preparation.

New Calhoun (FIGS. 19-23).- -Specimens from New Calhoun are poorly preserved due to the growth of pyrite crystals (FIG. 19). Chlamydospores reach $440 / \mathrm{xm}$ in diam and exhibit two walls when viewed in transmitted light. When specimens are scanned, considerable layering is observed in both walls, and is particularly

FIGS. 1-3. Lower Devonian chlamydospores from the Gaspe (Cornell University Paleobotanical Collection Type 198). 1. Several chlamydospores in inner cortex of Psilophyton dawsonii, x 105. 2. Chlamydospores showing nature of double walls. Note separation of walls into several layers, $\mathbf{x} 300$. 3. Section through portion of outer wall. Arrow indicates outer surface, x 10,000. FIGS. 4-9. Lower/ Middle Pennsylvanian chlamydospores from Lewis Creek (C. B. 1746 D). 4. Chlamydospores showing thick outer and thinner inner walls, $x$ 120. 5. Detail of chlamydospore walls, $x 200$. 6. Broken chlamydospore showing inner surface of outer wall and both surfaces of inner wall, $x 300$. 7. Section through outer and inner wall of chlamydospore. Note compact layers (arrows) and loosely arranged layers, x3000. 8. Detail of outer wall, $x \mathbf{1 0 , 0 0 0}$. 9. Detail of inner wall, $x \mathbf{1 0 , 0 0 0}$.

FIgS. 10-14, 18. Middle Pennsylvanian chlamydospores from West Mineral (C. B. 7854 B). 10. Chlamydospore with subtending hypha. Arrow indicates inner of three walls, $x$ 200. 11. Detail of middle wall, x500. 12. Chlamydospore with three walls. Note thickness of outer wall, x500. 13. Detail of spongy outer wall, $x 2500$. 14. Multiple layers of outer wall, x 10,000. FIGS. 15-17. Upper Pennsylvanian chlamydospores from Berryville (C. B. 6495 C). 15. Thick outer wall illustrating fibrillar organization. Note smooth, fragmented surface, x200. 16. Two-walled chlamydospore, x 200 . 17. Outer surface of outer wall of chlamydospore, $\mathbf{x 0 0}$. 18. Section through layered wall of chlamydospore. Note organization of solid and spongy layers, $\mathbf{x} 4000$.

FIGS. 19-23. Upper Pennsylvanian chlamydospores from New Calhoun (C. B. 6311 B). 19. Two-walled chlamydospore containing dark pyrite crystals, $x$ 110. 20. Detail of separating wall layers, $x$ 450. 21. Chlamydospore walls illustrating extensive separation, $x 250$. 22. Chlamydospore with smooth inner wall and relatively little separation of wall layers, $x 200$. 23. Section through portion of outer wall. Note compact and loosely arranged areas, $x$ 5000. FIGs. 24-26. Upper Pennsylvanian chlamydospores from Steubenville (C. B. 9773 F). 24. Chlamydospore with two walls, x130. 25. Outer and inner walls of chlamydospore with some separation of wall layers, $x 200.26$. Section through outer and inner wall. Note marginal compact regions and inner spongy areas, $x \mathbf{5 0 0 0}$. 
Mycologia

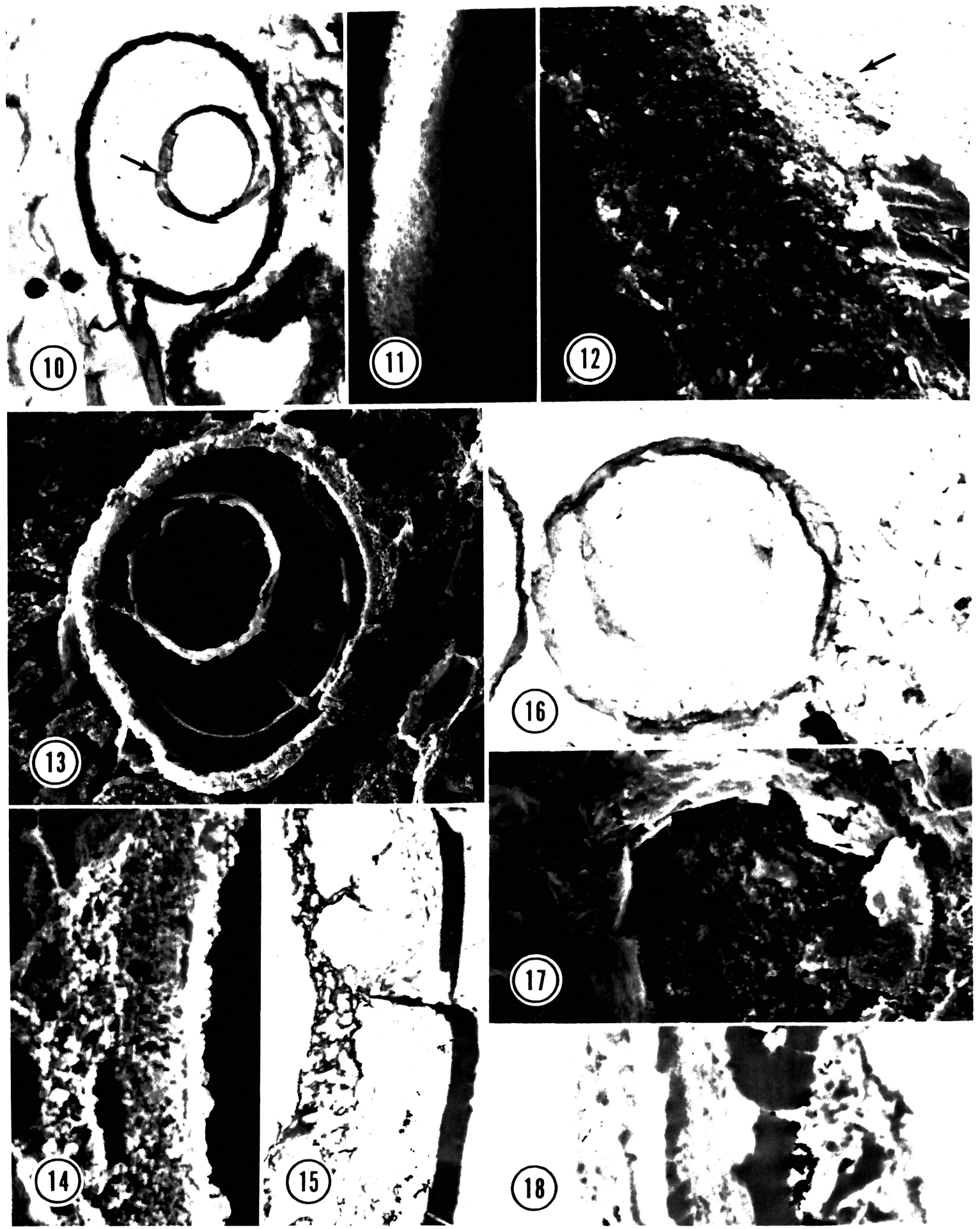



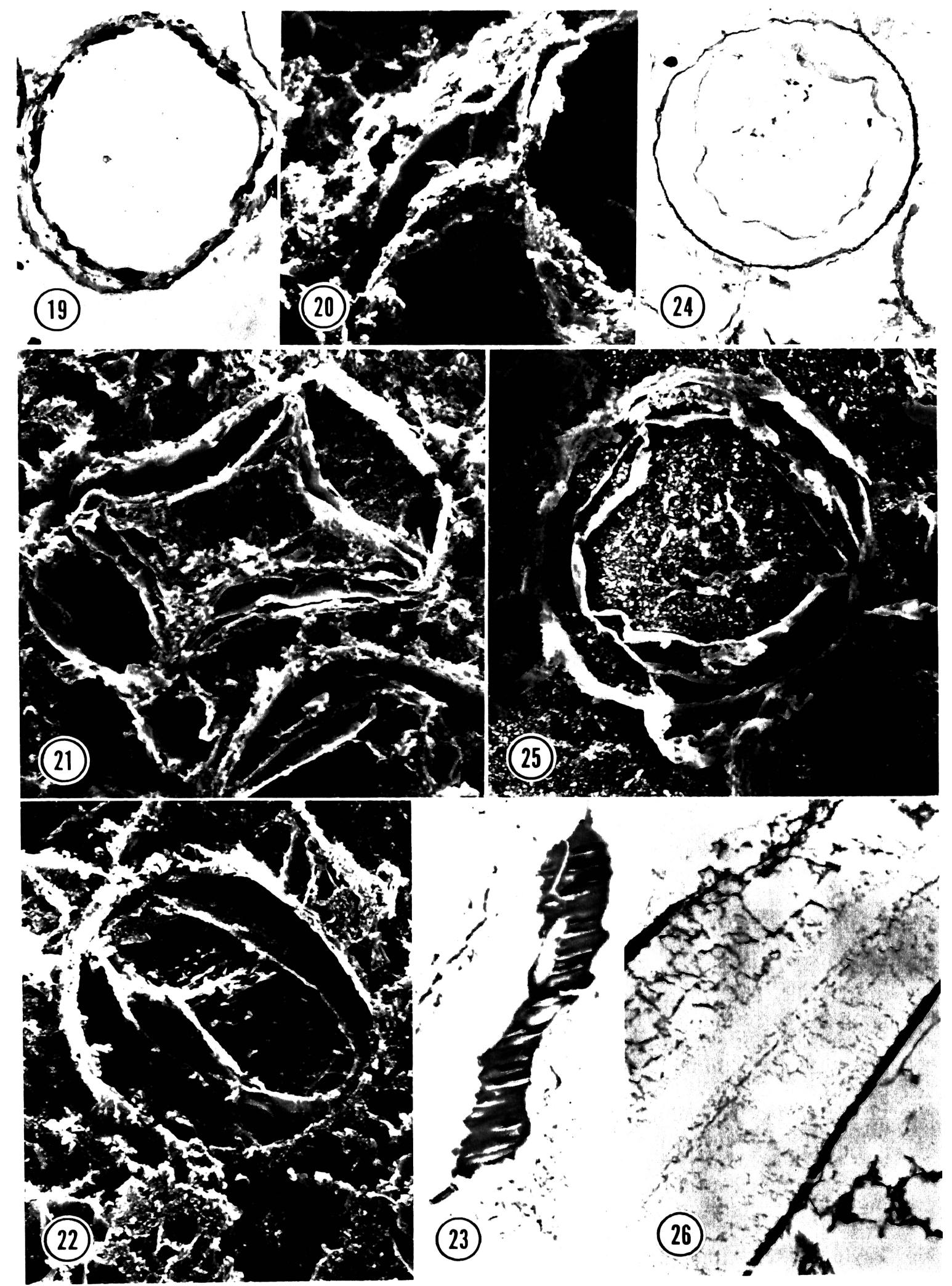
prominent in the inner wall (FIGS. 20, 21). Ultrathin sections of this poorly preserved tissue demonstrate the presence of a uniform electron-dense layer comparable to that seen in specimens from other localities, as well as material on either side which probably represents regions of more loosely arranged tissue (FIG. 23). Other areas of the wall were too poorly preserved to yield useful ultrastructural information.

Steubenville (FIGS. 24-26).-Chlamydospores from this site reach 340 /im in diam and are typically two-walled. Both walls are approximately $4{ }^{\wedge} \mathrm{ni}$ thick, although the outer one may in some cases be slightly thicker. Separation occurs in both walls, and is particularly characteristic of the inner wall (FIG. 25). In section view, each wall is two-layered. Both the outer layer of the outer wall and the inner layer of the second wall consist of a solid, electron-dense substance, while the inner layers are loosely arranged (FIG. 26).

\section{DISCUSSION}

The organization of the walls of resistant spores has been a major criterion in the taxonomy of the Endogonaceae (e.g., Hall and Fish, 1979; Schenck and Smith, 1982; Walker, 1983). Walker (1983) has suggested that emphasis be placed on the structure of the wall as seen in transmitted light since this can be determined more readily than ultrastructural detail. To standardize descriptions, recent authors have used line diagrams and proposed a uniform terminology to describe wall layers (Mosse, 1970c; Walker, 1983). Walker (1983) recognized four types of walls in modern endogonaceous spores. The first of these, termed the evanescent wall, is lost as the spore matures and may be easily missed when viewed in

transmitted light. Because of its delicacy and impermanence this type of wall is also likely to be absent in fossil chlamydospores. The second type, the unit wall, is a consistent feature of spores of the same species and level of maturation. Typically, it is rigid and consists of a single layer, and would no doubt be preserved in the fossil record. A third type of wall, the laminated wall, consists of "more or less tightly fused layers that do not differ in texture" (Walker, 1983). Because they sometimes separate when spores are crushed their layers may be mistaken for unit walls. However, if the original wall is laminated, the number of separated layers may be expected to vary from spore to spore. The fourth type of wall is the membranous wall, a thin, somewhat elastic layer which often shrinks during plasmolysis and probably will not break when the spore is crushed. This wall is difficult to distinguish from a thin unit wall in extant material, and would probably be indistinguishable in most fossil spores.

Wall structure, as seen in transmitted light, is relatively consistent among the Paleozoic spores examined. Chlamydospores typically possess two or three separate walls. The outer, thicker wall appears to be single in transmitted light and probably corresponds to the unit wall described by Walker (1983). The inner wall or walls do not exceed the outer wall in thickness, and may, in some instances, be substantially thinner. These layers probably represent either membranous walls or additional unit walls. It is also possible that in some spores the third layer may be the wall of an endoparasitic chytrid (Pirozynski, pers. commun.). Neither a well-defined evanescent wall nor a clearly laminated wall has been observed in any of the specimens we have examined in transmitted light.

Scanning electron microscopy has occasionally been applied to the study of the wall structure of endogonaceous spores (e.g., Ames and Linderman, 1976; Rose et al., 1979; Walker and Trappe, 1981; Tewari et al., 1982; Wagner and Taylor, 1982). Although such studies are few they have increased our understand- 
ing of wall organization and have consistently revealed complexity which is not recognized with transmitted light. This is apparent when the walls of fossil spores are compared in transmitted light and scanning electron microscopy. For example, both the inner and outer walls of chlamydospores from the Gaspe and New Calhoun seem to be single-layered in transmitted light and multilayered at higher magnifications. The presence of these layers may indicate a laminated wall despite the lack of visible layering in transmitted light, or simply reflect damage to the material during preparation. In either case, it is a consistent character among specimens from these two localities and may reflect some feature of wall composition and/or organization. Striking differences are also seen in the material from West Mineral. In transmitted light the outer wall appears to be solid and homogeneous while at higher magnifications it is spongy.

Transmission electron microscopy further demonstrates the complexity of the walls of fossil endogonaceous chlamydospores. Unfortunately, these techniques have not been widely applied to extant material. To our knowledge, the spores of only four extant species of endogonaceous fungi have been examined at the ultrastructural level. Best known is the wall structure of "honey-colored sessile Endogone spores" (Mosse, 1970c), now classified as Acaulospora laevis Gerdemann \& Trappe. Mosse provided a detailed description of the structure and development of these spores (Mosse, 1970a-c). Spores of Gigaspora margarita Becker \& Hall have also been examined at the ultrastructural level (Sward, 1981), and Bonfante-Fasolo and Scannerini (1976) have illustrated the ultrastructure of Endogone flammicorona Trappe \& Gerdemann. The sole TEM study of the spores of Glomus is that of Bonfante-Fasolo and Vian (1984) who discussed the ultrastructure of mature spores of Glomus epigaeum Daniels \& Trappe. They found the spores to consist of a homogenous outer wall and a complex inner wall separated by an electron-dense region. The outer wall was composed of parallel fibrils. This pattern was disrupted by alkali extraction. The inner wall was formed from microfibrils arranged in ten to twelve arcs forming the "bow-shaped layer." The curvature of the arcs decreased toward the inner part of the wall which showed randomly oriented microfibrils (Bonfante-Fasolo and Vian, 1984).

Lack of information concerning the range of variability of wall structure among extant endogonaceous chlamydospores (as well as other types of resistant fungal spores) at the ultrastructural level coupled with a lack of information concerning wall ontogeny in fossil chlamydospores limits the comparisons which can be drawn. Both fossil and extant chlamydospores are characterized by a thick, layered wall. Typically, the walls of the extant spores are more complex then those of the fossils, both in respect to the number of layers and in their structural variability. In both types of spores a solid, amorphous, electron-dense component is present, although this is minimal in $G$. epigaeum. The spongy construction of some wall layers in the fossils is absent in the living spores. In turn, a tripartite membrane, a layer with a regular periodicity, electron-lucent layers, and layers with specifically oriented microfibrils which are present in the spores described by Mosse (1970c), Sward (1981), and Bonfante-Fasolo (1983) and Bonfante-Fasolo and Vian (1984) are absent in the fossils. Although few extant endomycorrhizal species have been examined, the presence of regularly arranged microfibrils seems to be widespread in the Endogonaceae. Their absence in the fossil spores is noteworthy, but may not necessarily reflect original structural differences. Recent chemical studies on coal ball constituents (Hatcher et al, 1982) suggest that the original chemical components of plant cells such as cellulose or lignin are modified during fossilization. In this case, the absence of microfibrillar patterns characteristic of these substances is not surprising. On the other hand, Smoot and Taylor (1984) report the presence of distinct fibrillar structures in the sieve areas of Pennsylvanian age 
fern phloem, and suggest that in the absence of preserved cellulose, the fibrillar pattern may represent a replication of the original cellulose fibrils in crystalline material.

Despite the considerable similarity in structure illustrated in light and scanning studies (Wagner and Taylor, 1982), there are undeniable differences in the ultrastructure of the fossil and extant chlamydospores which are presently known. However, in view of the variability of wall structure in extant spores which is visible even in transmitted light, we expect considerable variation at the ultrastructural level. It should be noted, however, that the fossil forms are also similar to the resistant sporangia of the chytrid, Allomyces (Skucas, 1967). Mosse (1970c) also noted the resemblance between these sporangia and spores of Acaulospora. At the present time, without additional information concerning the ultrastructure of extant spore walls, further comparison is not possible.

The paucity of information concerning the variability of wall structure and its causes among modern chlamydospores hinders interpretation of variability among fossils. The material examined in the present study illustrates a general increase in wall complexity through time. This is seen most dramatically between the Devonian and Pennsylvanian, and again between the Pennsylvanian and the present, and to a lesser degree between the Lower and Middle Pennsylvanian. The increase in complexity, and in the variety of component layers, may represent evolutionary change. Other differences such as variety in wall thickness, the amount of wall splitting, or the sponginess characteristic of the chlamydospores from West Mineral are more difficult to evaluate. At this point, it is often not possible to distinguish evolutionary differences from those reflecting ecological and developmental factors, or levels of specific variation. In the future a better understanding of extant forms may provide a basis for such interpretation.

Perhaps the most important question involving Paleozoic chlamydospore-like fossils concerns their role in endomycorrhizal associations. If symbiosis played a major role in the development of the vascular land flora, as suggested by Pirozynski and Malloch (1975), a fossil history of mycorrhizae would be expected throughout the Paleozoic. Because of the problems inherent in demonstrating a physiological relationship based on morphological evidence, it is difficult to evaluate the validity of this thought-provoking suggestion. However, several lines of evidence are relevant to this hypothesis.

First of these is the demonstration of fossils that are morphologically similar to the extant VAM fungi. Extant endomycorrhizal fungi typically produce vesicles, thick-walled spores, arbuscules, and hyphae which often coil and loop. Thickwalled chlamydospores are the most common of these structures in the fossil record and are also the most thoroughly evaluated. Specimens described by Wagner and Taylor (1982) which demonstrate hyphal attachment are the most convincing evidence to date of fossil Endogonaceae. Vesicles similar in appearance to those of modern endogonaceous species have also been reported in Paleozoic plants including Rhynia and Asteroxylon (Kidston and Lang, 1921), a coenopterid fern (Andrews and Lenz, 1943), and cordaite roots (Osborn, 1909; Halket, 1930; Cridland, 1962). None of these has been examined at the electron microscope level.

Fossil hyphae which show some degree of clumping, coiling or looping have also been reported (Weiss, 1904; Andrews and Lenz, 1943) and coiled intracellular hyphae are characteristic of certain VA mycorrhizae (Cox and Sanders, 1974; Kinden and Brown, 1975a, b; Brown and King, 1982; Taber and Strong, 1982). It is exceedingly difficult to evaluate fossil hyphae. However, the presumed hyphal knots illustrated by Weiss (1904) as solid black spheres with radiating extensions are not, in our opinion, convincingly fungal, nor do they show distinctive en- 
dogonaceous features. The "dense tangles of mycelium" illustrated by Andrews and Lenz (1943) are also problematic. Although the specimens in question are undoubtedly infected by fungi and probably exhibit vesicle-like structures, the tangled hyphae show many features of a resinous or gummy mass. The irregularity in size and shape of hyphal strands, anastomoses, and fusion into a "nearly spherical amber colored sphere" suggest a non-fungal origin for this material.

The occurrence of chlamydospores and vesicles in conjunction with hyphae in plant tissue suggests the presence of fungi similar to the modern Endogonaceae. However, these structures alone are not conclusive proof for Paleozoic mycorrhizae since extant endogonaceous fungi are not all known to be mycorrhizal (Trappe and Schenck, 1982). Perhaps the most reliable structural indicator of this type of physiological relationship is the arbuscule since it is through this organ that metabolic exchange occurs. Among modern VAM fungi, the arbuscule is a highly branched structure usually formed within the cortex of roots (Kinden and Brown, 1975a, b). Arbuscules are transitory, and eventually break down to form a mass of material in the center of the cortical cells. Reports of fossil arbuscules are few and even more problematic. Cridland (1962) reexamined reputed arbuscules in Amyelon radicans (Osborn, 1909; Halket, 1930) and discounted all claims of mycorrhizae in that material. Rather, he concluded that the so-called arbuscules were actually a dark secretory substance which became fibrillar upon drying. Similarly, Cridland (1962) found no evidence for arbuscules in Radiculites reticulars as reported by Lignier (1906) or Zimmermann (1933).

A second and third type of data which is relevant to the evolutionary role of mycorrhizae concerns the distribution of chlamydospores in the fossil record. Statistically valid data on the occurrence of chlamydospores in particular genera or groups of vascular plants are lacking with respect to fossils, and even qualitative reports are often contradictory. For example, Pirozynski (1981) comments that endotrophic symbiosis was well represented in the arborescent Carboniferous ancestors of the modern Equisetales, while Berch and Kendrick (1982) suggest that the lack of mycorrhizae in these plants may have been responsible for their evolutionary demise. Similarly, the distribution of chlamydospores in the various organs of fossil plants is not well documented. While chlamydospores are often present in the subterranean portions of certain Pennsylvanian coal ball plants such as Psaronius and Stigmaria they also occur in other plant organs and in the coal ball matrix. Furthermore, they are present in the aerial axes of more primitive plants such as Psilophyton which do not yet show histological differentiation between roots and stems (Stubblefield and Banks, 1983). Endogonaceous fungi, once believed to be restricted to roots, are now known from the xylem of Tradescantia virginiana (Taber and Strong, 1982) and the rhizomes, scale-like leaves, and xylem of ginger (Taber and Trappe, 1982). However, since their role in these portions of the plant is unclear, it is not possible to evaluate their presence in aerial parts of fossil plants. While the occurrence of chlamydospores in Paleozoic stems clearly does not preclude a symbiotic relationship, a consistent association with the underground parts of specific plants would be expected if mycorrhizae are indeed a major factor in evolution. An accurate, statistically valid survey is needed to evaluate conflicting reports concerning the distribution of these fungal structures.

Ultrastructural examination of six different types of Paleozoic chlamydospores provides additional evidence concerning an interesting group of ancient fungi, and illustrates the complexity of these early organisms. The structural organization of these forms is consistent with past interpretations which relate them to extant VAM-forming Endogonaceae. However, their affinities will not be firmly established without more information regarding the ultrastructure of the walls of re- 
sistant fungal spores. The occurrence of this type of spore in conjunction with hyphae and vesicles suggests the presence of endogonaceous fungi in the Paleozoic. However, the presence of ultrastructural differences coupled with the absence of well-defined arbuscules, and the lack of data concerning the distribution of VAMlike fungi in the fossil record, requires that the existence of Paleozoic mycorrhizae be considered conjectural. At the present our understanding of the role of mycorrhizae in the evolution of land plants is largely speculative. As further information regarding the identity, structure, and distribution of fossil fungi becomes available, paleomycology may play an increasing role in evaluating the history of VA mycorrhizae in symbiotic associations and perhaps, the evolution of land plants.

\section{ACKNOWLEDGMENTS}

The authors wish to thank Dr. Harlan P. Banks of the Section of Plant Biology, Cornell University, Ithaca, New York for providing the Devonian specimens, and Dr. L. H. Rhodes of the Department of Plant Pathology, The Ohio State University, and Dr. L. F. Grand of the North Carolina State University for providing specimens of extant VA fungi for examination by the authors. We also thank Dr. Rhodes, and Dr. K. A. Pirozynski of the Paleobiology Division, National $\mathrm{Mu}-$ seums of Canada, Ottawa, for their helpful comments. Finally, we wish to acknowledge Dr. Barry H. Rosen's skillful assistance with transmission electron microscopy. This research was supported in part by National Science Foundation grant DEB-8213060.

\section{LITERATURE CITED}

Ames, R. N., and R. G. Linderman. 1976. Acaulospora trappei sp. nov. Mycotaxon 3: 565-569.

Andrews, H. N., and L. W. Lenz. 1943. A mycorrhizome from the Carboniferous of Illinois. Bull. TorreyBot. Club 70: 120-125.

Bartnicki-Garcia, S. 1970. Cell wall composition and other biochemical markers in fungal phylogeny. Pp. 81-103. In: Phytochemical phylogeny. Ed., J. B. Harborne, Symp. Phytochemical Society, Univ. Bristol, 1969. Academic Press, New York.

Berch, S. M., and B. Kendrick. 1982. Vesicular-arbuscular mycorrhizae of southern Ontario ferns and fern allies. Mycologia 74: 769-776.

Bonfante-Fasolo, P. 1983. Electron microscopic cytochemical study of cell wall in Glomus epigaeum spore. Abstr. 3rd Internat. Mycol. Congr. Tokyo, p. 392.

, and S. Scannerini. 1976. The ultrastructure of the zygospore in Endogone flammicorona Trappe and Gerdemann. Mycopathologia 59: 117-123.

, and B. Vian. 1984. Wall texture in the spore of a vesicular-arbuscular mycorrhizal fungus. Protoplasma 120: 51-60.

Boullard, B., and Y. Lemoigne. 1971. Les champignons endophytes du "Rhynia gwynne-vaughanir K. et L. Le Botaniste 54: 49-89.

Brown, M. F., and E. J. King. 1982. Morphology and histology of vesicular-arbuscular mycorrhizae A. Anatomy and cytology. Pp. 15-21. In: Methods and principles of mycorrhizal research. Ed., N. C. Schenck. Amer. Phytopathol. Soc., St. Paul, Minnesota.

Butler, E. J. 1939. The occurrences and systematic position of the vesicular-arbuscular type of mycorrhizal fungi. Trans. Brit. Mycol. Soc. 12: 274-301.

Cox, G., and F. Sanders. 1974. Ultrastructure of the host-fungus interface in a vesicular-arbuscular mycorrhiza. New Phytol. 73: 901-912.

Cridland, A. A. 1962. The fungi in cordaitean rootlets. Mycologia 54: 230-234.

Daghlian, C. P., and T. N. Taylor. 1979. A new method of isolating pollen and spores from acetate peels for scanning electron microscopy. Rev. Palaeobot. Palynol. 27: 85-89.

Good, C. W. 1975. Pennsylvanian-age calamitean cones, elater-bearing spores, and associated vegetative organs. Palaeontographica 153B: 28-99.

, and T. N. Taylor. 1970. On the structure of Cordaites felices Benson from the Lower Pennsylvanian of North America. Palaeontology 13: 29-39.

Hall, I. R., and B. J. Fish. 1979. A key to the Endogonaceae. Trans. Brit. Mycol. Soc. 73: 261-270.

Halket, A. C. 1930. The rootlets of Amyelon radicans Will., their anatomy, their apices and their endophytic fungus. Ann. Bot. (London) 44: 865-905. 
Hatcher, P. G., P. C. Lyons, C. L. Thompson, F. W. Brown, and G. E. Maciel. 1982. Organic matter in a coal ball: peat or coal? Science 217: 831-833.

Kelly, A. P. 1950. Mycotrophy in plants. Lectures on the biology of mycorrhizae and related structures. Chronica Botanica Co., Waltham, Massachusetts. 223 p.

Kidston, R., and W. H. Lang. 1921. On Old Red Sandstone plants showing structure, from the Rhynie Chert Bed, Aberdeenshire. Part V. Trans. Roy. Soc. Edinburgh 52: 855-902.

Kinden, D. A., and M. F. Brown. 1975a. Electron microscopy of vesicular-arbuscular mycorrhizae of yellow poplar I. Characterization of endophytic structures by scanning electron stereoscopy. Canad. J. Microbiol. 21: 989-993.

, and 1975b. Electron microscopy of vesicular-arbuscular mycorrhizae of yellow poplar. III. Host-endophyte interactions during arbuscular development. Canad. J. Microbiol. 21: 1930-1939.

Lignier, O. 1906. Radiculites reticulatus, radicelle fossile de Sequoinee. Bull. Soc. iSot. France 53, (Ser. 4) 6: 193-201.

Mamay, S. H. 1957. Biscalitheca, a new genus of Pennsylvanian coenopterids, based on its fructification. Amer. J. Bot. 44: 229-239.

McGregor, D. C. 1977. Lower and Middle Devonian spores of eastern Gaspe, Canada. Palaeontographica 163B: 111-142.

Mosse, B. 1970a. Honey-colored, sessile Endogone spores: I. Life history. Arch. Mikrobiol. 70: 167175.

- 1970b. Honey-colored, sessile Endogone spores: II. Changes in fine structure during spore development. Arch. Mikrobiol. 74: 129-145.

. 1970c. Honey-colored, sessile Endogone spores: III. Wall structure. Arch. Mikrobiol. 74: 146-159.

Osborn, T. G. B. 1909. The lateral roots of Amyelon radicans Will., and their mycorrhiza. Ann. Bot. (London) 23: 603-611.

Phillips, T. L. 1980. Stratigraphic and geographic occurrences of permineralized coal-swamp plantsUpper Carboniferous of North America and Europe. Pp. 25-92. In: Biostratigraphy offossil plants. Ed., D. L. Dilcher and T. N. Taylor. Dowden, Hutchinson and Ross, Stroudsburg, Pennsylvania.

Pirozynski, K. A. 1981. Interactions between fungi and plants through the ages. Canad. J. Bot. 59: 1824-1827.

, and D. W. Malloch. 1975. The origin of land plants; a matter of mycotrophism. BioSystems 6: $153-164$.

Rose, S., B. A. Daniels, and J. M. Trappe. 1979. Glomus gerdemannii sp. nov. Mycotaxon 8: 297301.

Roth well, G. W. 1976. Petrified Pennsylvanian age plants of eastern Ohio. Ohio J. Sci. 76: 128-132.

Schenck, N. C., and G. Smith. 1982. Additional new and unreported species of mycorrhizal fungi (Endogonaceae) from Florida. Mycologia 74: 77-92.

Sela, J., and A. Boyde. 1977. Cyanide removal of gold from SEM specimens. J. Microscopy 3: 229231.

Skucas, G. P. 1967. Structure and composition of the resistant sporangial wall in the fungus Allomyces. Amer. J. Bot. 54: 1152-1158.

Smoot, E. L., and T. N. Taylor. 1984. The fine structure of fossil plant cell walls. Science 225: 621623.

Stubblefield, S. P., and H. P. Banks. 1983. Fungal remains in the Devonian trimerophyte Psilophyton dawsonii. Amer. J. Bot. 70: 1258-1261.

Sward, R. J. 1981. The structure of the spores of Gigaspora margarita. I. The dormant spore. New Phytol. 87: 761-768.

Taber, R. A., and M. E. Strong. 1982. Vesicular-arbuscular mycorrhiza in roots and xylem of Tradescantia. Mycologia 74: 152-156.

, and J. M. Trappe. 1982. Vesicular-arbuscular mycorrhiza in rhizomes, scale-like leaves, roots, and xylem of ginger. Mycologia 74: 156-161.

Tewari, J. P., W. P. Skoropad, K. G. Mukerji, and S. Mishra. 1982. Surface morphology of Glomus macrocarpum chlamydospores. Trans. Brit. Mycol. Soc. 79: 364-366.

Trappe, J. M., and N. C. Schenck. 1982. Taxonomy of the fungi forming endomycorrhizae. Pp. 19. In: Methods and principles of mycorrhizal research. Ed., N. C. Schenck. Amer. Phytopathol. Soc., St. Paul, Minnesota.

Wagner, C.W., and T. N. Taylor. 1981. Evidence for endomycorrhizae in Pennsylvanian age plant fossils. Science 212: 562-563. , and 1982. Fungal chlamydospores from the Pennsylvanian of North America. Rev. Palaeobot. Palynol. 37: 317-328.

Walker, C. 1983. Taxonomic concepts in the Endogonaceae: spore wall characteristics in species descriptions. Mycotaxon 18: 443-445.

, and J. M. Trappe. 1981. Acaulospora spinosa sp. nov. with a key to the species of Acaulospora. Mycotaxon 12: 515-521. 
Weiss, F. E. 1904. A mycorrhiza from the Lower Coal Measures. Ann. Bot. (London) 18: 255-267. Wolf, F. A., and F. T. Wolf. 1947. The fungi. Vol. 2. Wiley, New York. 538 p.

Zimmermann, W. 1933. Palaobotanische und Phylogenetische Beitrage, 1-4. Palaeobiologica 5: 321 348.

Accepted for publication July 10, 1984 